\title{
A Feasibility Solution of a Synchronous Generator for Optimisation of the System Power Stability using an Integrated Development Environment of Visual Basic-Excel
}

\author{
Emad Al-Mahdawi
}

\begin{abstract}
Power systems are considered highly non-linear because the environment in which they operate keep changing and hence require iterative mathematical techniques to analyse them. Such changes have a resultant effect on the system`s stability. Fluctuations in parameters are experienced in loads across the networks of the system, generator`s outputs, network topology and other operating parameters. Practically, there is no analytical solution exists for solving the problem of stability. On the other hand, there are techniques available to obtain an acceptable approximate solution of such a problem, known as digital simulation. Runge-kutta method is one of these techniques which has been used broadly as it calculates every step in a sequence of sub-steps. The method relies on a complex mathematical modelling of the synchronous generator with the help of Park-Gorev`s transformation, for the sake of simplicity and intuitiveness the method is used to analyse and study the complex equations of the three-phase synchronous generator. Generally, the system is said to be stable if the opposing forces within it are balanced and at a perfect equilibrium. The aims of this research are to establish the effects of synchronous generator`s design and transient conditions upon power system stability with the help of Embedded Microsoft Excel Sheet based on Power System Stability Analysis (EMES-PSS), using the Runge-Kutta integration method. The study has proved that EMES-PSS can find the limits of Salient and Non-Salient machines stability when changing their essential parameters. The optimisation solutions of the power system stability problem can be achieved by using basic computational resources. The software can also be used on a number of modern tablets e.g., Apple`s tablets.
\end{abstract}

Keywords - Synchronous Machine, Modelling, Stability, Runge-Kutta, Visual Basic.

\section{INTRODUCTION}

The development of energy within developed and developing countries is characterised by a steady increase in electrical power generation due to the preferential development of thermal and hydraulic power plants with aggregates of large single capacities. The increase of the nominal power of the generators is the main direction of the development of turbo and hydro-generators. The most advanced manufacturers of generators have reached single capacity of turbo-generators of 1300 - $2000 \mathrm{MW}$ and hydro generators $700-800 \mathrm{MW}$.

Revised Manuscript Received on February 05, 2020.

* Correspondence Author

Dr.Emad Al-Mahdawi*, Department of Electrical Engineering, MidKent College, Kent - United Kingdom emadalmahdawi@yahoo.com

(C) The Authors. Published by Blue Eyes Intelligence Engineering and Sciences Publication (BEIESP). This is an open access article under the CC BY-NC-ND license (http://creativecommons.org/licenses/by-nc-nd/4.0/)
The main driving factors are the economy of production, the reduction of capital costs for facilities (building of thermal power plants and high-pressure processing facilities), as well as the economy of operation [16]. There are some constraints on the power of the interconnected network, which includes a powerful generator or a power plant. It is generally considered that the power of the largest generator should not exceed $0.5 \%$ of the power of the system to which it is connected, as well as the level of short-circuit currents.

The operation of a power system depends mostly on the reliable service to the loads. Flawlessly and continuously, the loads must be fed at a constant frequency and voltage within permissible variations. According to the Electricity Safety, Quality and Continuity Regulation (ESQCR) of England [24], the permissible high voltage variation on $132 \mathrm{kV}$ and below is between $\pm 6 \%$. However, the permissible voltage variation is $\pm 10 \%$ for the voltages above $132 \mathrm{kV}$. In regards to the frequency, the allowable frequency variation is $\pm 1 \%$.

To keep the reliability and continuity, the synchronous generators should run in parallel and with adequate capacity to meet the load demand. The reliable electrical service maintains the integrity of the power network. Synchronous machines are controlled by synchronising forces; therefore, they do not easily fall out of step under normal conditions. However, circumstances do arise, such as a fault on the power network, failure in some parts of power network equipment and sudden application or increase of loads.

Due to the fact that the high-voltage transmission system links the generating power plants and the load centres, disconnections in this network may hinder the flow of power to the load.

Nevertheless, random changes could happen in demand at all times, with subsequent adjustments of generating units leading to change from one equilibrium state to another. However, adjustment to the new operating condition is called the transient period. During this period, synchronism may frequently be lost, or growing fluctuations may occur over a transmission line, eventually leading to its tripping.

Generally, a system is said to be stable if it can regain its normal equilibrium state after an imposed disturbance is removed. Power system stability is referenced from a particular initial condition of operating. 


\section{A Feasibility Solution of a Synchronous Generator for Optimisation of the System Power Stability using an Integrated Development Environment of Visual Basic-Excel}

As such, a clear definition of the system stability states that a system is said to be stable if the opposing forces within it are balanced and at a perfect equilibrium. Instability is caused by imbalance sustained when the opposing forces are not equal. The resulting disturbance causes instability within the power system [8].

According to [12], when a system is exposed to intense disturbance that could otherwise be described as transient, its stability changes. The change is proportional to its initial operating condition and the disturbance's nature causing the change in stability. In addition, the disturbance has a magnitude that can either be small or large. Minor modifications are experienced in the form of the differences in the load's size. Systems are capable of adapting to such changes to ensure that they maintain optimal performance. Such systems operate with the correct index under such changes and conditions. They meet the load demand successfully. They are also capable of surviving several disturbances that might be severe in nature. Serious disturbances include short-circuits on transmission lines or the loss of large generators. Furthermore, the power-angle relationships and the dynamics of the angles of the generator rotors significantly affect the aspect of stability of the power systems.

The stability of a power system can be established when a transient disturbance is applied to it. If it is stable, it reaches a new level and state of equilibrium, and the entire system remains intact practically. The proper situation of the system is restored by the use of human operators and the application of automatic controls. A run-down situation or run-away is experienced if the system is unstable. Instability is caused by such occurrences as decreasing voltages in the bus progressively or increasing the angular separation and distance between the rotors of generators. If the unstable condition is not rectified fast enough, it could result in cascading outages. Persistent cascading outages may result in the shutting down of a portion or entire system [12].

Much of the equipment is involved in the response to a system disturbance. For instance, variations in the speed of the rotor of the machine, power flows, and network bus voltages are caused by a fault on a critical element of the system. These parameters of the system occur when the key component is isolated by protective relays. The regulators of the transmission and generator voltages are actuated by the variations in the voltage. The prime mover governors are then actuated by the changes in the speed of the generator. The individual characteristics of the frequencies and voltages determine the extent to which the variations and changes affect loads of the power system.

Protection devices are usually used to protect equipment of the power systems from disturbances and changes in their parameters to sustain the performance of the power system network. These devices respond to changes and variations in the variables of the system [18]. Modern power systems are characterised by the incorporation of high-order multivariable processes. As such, their performances are affected by numerous devices that have varied characteristics and response rates. Thus, variability depends on the operating mode of the system, its topology, and the nature of the disturbance.
The primary challenge involved in power systems is maintaining stability in the operation of synchronous systems and machines. All power systems depend on synchronous machines to generate electrical power. As a result, the synchronous machine must always remain in a state of synchronism. Synchronism only means that the machine is 'in step' with the parameters and disturbances affecting its performance. Loss of synchronism in the machines leads to instability of the power systems [5].

System controls, protections, generator controls, and prime mover controls are the driving parameters in case the load/generation ratio becomes a significant mismatch. The frequency of the system becomes unstable if the system is not coordinated properly. A system blackout may result due to the tripping of the generating units and loads. That shows the system might become unstable despite the fact that the synchronism of the machines is retained. The synchronism remains until it is tripped by protections such as underfrequency [24].

Stability problems are usually complex and involve high dimensionality. As such, the right degree of detail and parameters of the system should be used to make simplified assumptions. Such assumptions are used to analyse the particular causes of problems such as instability of the systems. The information and results gathered could then be used to establish possible ways of minimising instability in systems.

\section{POWER SYSTEM STABILITY ANALYSIS}

The equilibrium state of restoring and disturbance forces is scientifically termed Stability. According to the severity of the perturbing condition, the stability of the power system is divided into four categories:

- Steady state stability happens when a small and slow disturbance occurs between the generation and load, leading to the establishment new steady-state operating condition with a new adjustment of the torque angles. There are several methods which improve system stability by improving steady-state stability. This can be achieved by using higher voltage level, employing additional parallel transmission line to reduce the high reactance of the transmission line, employing a series capacitive line compensation or by using static var compensators and flexible ac transmission systems (FACTS).

- Transient stability happens when a power system is subjected to a severe disturbance, short circuit, for a short time not exceeding 5 seconds. The stability of the system depends on both the severity of disturbance and initial operating condition.

- Dynamic Stability usually happens when the transient is maintained, therefore, it takes longer time, a few minutes.

Both the transient as well as dynamic stability is improved by short time fault clearing, fast reclosing of circuit breaker, single pole switching, employing large machine inertia, lower transient reactance, fast valve system responding, high gain excitation system and employing braking resistors [20, 25]. 
- Frequency stability occurs when the frequency dramatically reduces, e.g. $47 \mathrm{~Hz}$. This will lead to damage of steam turbines. However, hydraulic and thermal power plants are more robust. Further reduction in frequency will lead to worse scenarios that will most likely lead to disconnection. Deviation of the frequency has negative consequences. Firstly, it will lead to overload power transformers. Secondly, it negatively affects the performance of the AC motor drives which provide the cooling services for the entire system [6, 20].

\section{MATHEMATICAL MODELLING}

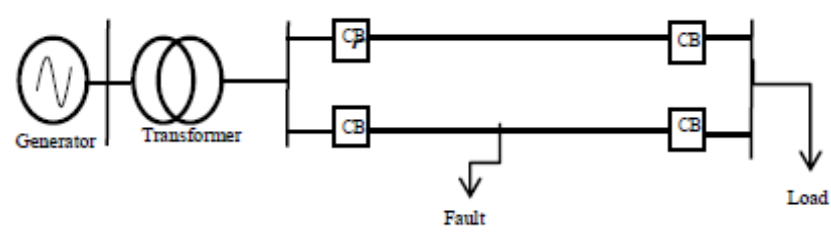

Fig.1 Simplified power network

A simplified power network has been implemented within this study consisting of a transformer and transmission line as shown in fig.1. This section seeks to establish whether or not a synchronous generator would still maintain its stability in the event of a fault in the system. Salient and non-salient synchronous rotors are taken into consideration.

Generally, synchronous generator is divided into salient and non-salient rotors [9]. It generates power and electricity from the compression of a fluid such a liquid or a gas. The stability, magnitude, and direction of the electric power generated depend on the torque of the inputs. From is the product of the mass of the object, perpendicular distance of the application of force, and the force of gravity acting on the object exerting the torque. Therefore, altering the essential parameters of the turbine have a significant impact on the synchronous generator's stability.

Under the condition of maintaining the system`s frequency, increasing the mass of the turbine increases the rotation of the generator. However, this may not bring about any significant effect on the stability of the generator, due to the fundamental fact that the speed is kept constant by the voltage in the grid and the current in the rotor and stator windings [14].

However, changing the parameters of the generator such as increasing the mass of the turbine, increases the magnitude of torque and consequently the power generated. It must be denoted that high increases in mass may destabilise the system for some generators [9, 23]. The stability of the system can thus be controlled by adjusting the mass of the turbine in salient and non-salient synchronous machines accordingly to certain levels. The software Embedded Microsoft Excel Sheet based on Power System Stability Analysis (EMES-PSS) has been designed to discover the limits of increment for the turbine`s mass for both salient and non-salient pole machines.

It should be pointed out that the dimensions of the generators are limited. Therefore, an increase in the unit fundamental physics and first principles of calculus, torque

power of the generator is achieved mainly by increasing the current densities in the stator and rotor windings, and this can be accomplished only by improving the cooling systems of the generators.

The simplified total power of the generator is proportional to the product of the following quantities [13]:

$$
\mathrm{S}=\mathrm{k} * \mathrm{D}_{\mathrm{i}}{ }^{2} * \mathrm{~L}_{\mathrm{t}} * \mathrm{~N} * \text { As } * \mathrm{~B}
$$

Where: $\mathrm{k}$ - constant depends on the number of

poles

$\mathrm{D}_{\mathrm{i}}$-Diameter of the stator boring,

$\mathrm{L}_{\mathrm{t}}$ - Active length of the stator core,

$\mathrm{N}$ - Number of rotor revolutions, rpm

As - The current density along the stator,

$\mathrm{Bav}_{\mathrm{av}}$ - Average flux density over a pole span, Tesla.

The stability of power systems is very critical in the engineering`s world. It assists with improving the effectiveness and efficiency of the transmitted power in transmission lines. As such, it is critically significant to conduct advanced studies to establish better methods of improving the control of power systems.

To ease the complexity and computational system modeling, the following assumptions are made in studying the stability:

1. The mechanical input power remains constant.

2. Damping power is negligible.

3. Each machine is represented by a constant transient internal voltage in series with a transient reactance.

4. Loads are considered as shunt impedances to ground with values determined immediately prior to the transient conditions.

The proposed generator to be controlled as studied in this work, is shown in Fig. 2. The synchronous machine equations are described in terms of Park-Gorev`s in d-q axis. The Park-Gorev's equations express the synchronous machines under transient conditions in both rotor and stator windings. These equations are described as follows [1, 19 and 23]:

Stator terminal voltage equations on $\mathrm{d}$ and $\mathrm{q}$ axis: $v_{d}=-R_{s} i_{d}-\omega \lambda_{q}+\lambda_{d}$

$$
v_{q}=-R_{s} i_{q}-\omega \lambda_{d}+\lambda_{q}
$$

$$
v=-R_{s} i-\frac{d(\phi)}{d t}=-R_{s} i-L_{s} \frac{d i}{d t}+e
$$

$$
\begin{aligned}
& \text { where: } i=\left[\begin{array}{l}
i_{a} \\
i_{b} \\
i_{c}
\end{array}\right] \\
& e=\left[\begin{array}{lll}
e_{a} & e_{b} & e_{c}
\end{array}\right]^{T} \text { is back electromotive force (emf) } \\
& v=\left[\begin{array}{ll}
v_{a} v_{b} & v_{c}
\end{array}\right]^{T} \text { is phase terminal voltage } \\
& \text { Direct and quadrature axis flux linkages: } \\
& \lambda_{d}=-L_{d} i_{d}+L_{m d}\left(i_{f d}+i_{k d}\right) \\
& \text { (4) } \lambda_{q}=-L_{q} i_{q}+L_{m q} i_{k q}
\end{aligned}
$$

Field terminal voltage:

$$
V_{f}=-R_{f} i_{f}-\frac{d \Phi_{f}}{d t}
$$

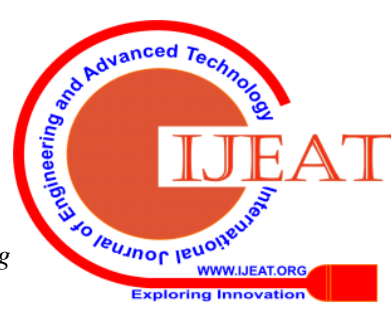


A Feasibility Solution of a Synchronous Generator for Optimisation of the System Power Stability using an Integrated Development Environment of Visual Basic-Excel

\begin{tabular}{|c|c|}
\hline $\begin{array}{l}\text { Fig. } 2 \text { Inductances of the Synchronous Machine } \\
{[14] .}\end{array}$ & Fig.3 Synchronous Inductances with Flux [10] \\
\hline q-axis $=$ & \begin{tabular}{c} 
air gap \\
$\Phi_{l d}$ \\
\hdashline$\Phi_{l d}$ \\
\end{tabular} \\
\hline
\end{tabular}

Excitation control input on direct axis:

$v_{f d}=R_{s} i_{f d}-L_{m d} i_{d}+L_{f d} i_{f d}+L_{m d} i_{k d}$

(7)

Damper winding equations where no voltage exists:

$0=R_{k d} i_{k d}-L_{m d} i_{d}+L_{m d} i_{f d}+L_{k d} i_{k d}$

$0=R_{k d} i_{k d}-L_{m d} i_{d}+L_{m d} i_{f d}+L_{k d} i_{k d}$

Table 1: synchronous machine essential parameters

\begin{tabular}{|l|l|}
\hline$i_{d,} i_{q}$ & Direct and quadrature axis stator current components, respectively. \\
\hline$i_{f d}$ & The field winding current \\
\hline$i_{k d,}, i_{k q}$ & Direct and quadrature axis damper winding current components. \\
\hline$R s, L s$ & The stator resistance and inductance \\
\hline$R_{f d}$ & The field resistance \\
\hline$R_{k d,} R_{k q}$ & The damper winding resistances \\
\hline$L_{d,} L_{q}$ & The direct and quadrature self-inductances \\
\hline$L_{f d}$ & The rotor self-inductance. \\
\hline$L_{k d,} L_{k q}$ & Direct and quadrature damper winding self-inductances. \\
\hline$L_{m d,} L_{m q}$ & Direct and quadrature magnetizing inductances, respectively. \\
\hline
\end{tabular}

\section{DYNAMIC MODELLING OF SYNCHRONOUS MACHINE}

When a synchronous machine is running, it produces an electromagnetic torque $\mathrm{T}_{\mathrm{e}}$ running at a synchronous speed $\omega_{s m}$. Under steady state operation, the mechanical torque $\mathrm{T}_{\mathrm{m}}=\mathrm{T}_{\mathrm{e}}$. In case of disturbance occurrence, the resultant between two torques will develop. This can be expressed by the law of rotation into [23]:

$J \frac{d_{\theta m}^{2}}{d t^{2}}=T_{j}=T_{m}-T_{e}$

(10)

Where: $\mathrm{J}$ is the moment of inertia of the combined turbine and generator

$\theta \mathrm{m}$ is the angular displacement of rotor w.r.t. stationary stator

Such that:

$\theta_{m}=\omega_{s m} t+\delta_{m}$

Where: $\omega_{s m}$ is the constant angular velocity

By taking the second derivative of $\theta_{m}$, substituting it in the law of rotation eq. (11) and multiplying with $\omega_{m}$ :

$J \omega_{m} \frac{d^{2} \delta_{m}}{d t^{2}}=M \frac{d^{2} \delta_{m}}{d t^{2}}=\omega_{m} T_{m}-\omega_{m} T_{e}=P_{m}-P_{e}$
Where: $\mathrm{M}$ is the inertia constant, $\mathrm{P}_{\mathrm{m}}$ and $\mathrm{P}_{\mathrm{e}}$ are mechanical and electromechanical power.

Equation 13 is termed a swing equation. The later can be converted into per unit system:

$\frac{2 H}{\omega_{s}} \frac{d^{2} \delta}{d t^{2}}=P_{m}-P_{e}=\quad M \frac{d^{2} \delta}{d t^{2}}=P_{m}-P_{e}$

Where: $M=\frac{2 H}{\omega_{s}} ; \delta=\frac{p}{2} \delta_{m} ; \omega=\frac{p}{2} \omega_{m} ;$

$\mathrm{p}=$ number of poles, $\omega_{m}=$ synchronous speed in mechanical radian/sec.

$\mathrm{H}=$ Machine Kinetic Energy / Rated MVA Capacity (another inertia constant)

However, it must be noted that the value of $\mathrm{M}$ is directly connected to the size of the machine. The larger the machine size, the extra will be inertia constant $\mathrm{M}$.

As the power $\mathrm{P}$ is invariant, therefore, the same power expression can be used in both the 0dq and abc. It is easy to show that,

$P=V_{a} i_{a}+V_{b} i_{b}+V_{c} i_{c}=\frac{3}{2} V_{d} i_{d}+\frac{3}{2} V_{q} i_{q}+3 V_{0} i_{0}$

By substituting equation $1 \& 2$ in 17 , the result can be expressed as follows:

$P=\omega \frac{3}{2}\left(\lambda_{d} i_{q}-\lambda_{q} i_{d}\right)+\frac{3}{2}\left(\frac{d \lambda_{d}}{d t} i_{d}-\frac{d \lambda_{q}}{d t} i_{q}\right)+3 \frac{d \lambda_{0}}{d t} i_{0}$

(15)

If the stator phase currents ia, ib, and ic are projected along the $d$ and $q$ axes of the rotor, the following relationships are obtained if the a axis is chosen as reference,

$$
\begin{gathered}
i_{q}=\sqrt{(2 / 3)} \times\left[i_{a} \sin \theta+i_{b} \sin \left(\theta-\frac{2 \pi}{3}\right)\right. \\
\left.+i_{c} \sin \left(\theta+\frac{2 \pi}{3}\right)\right] \\
i_{d}=-\sqrt{(2 / 3)} \times\left[i_{a} \sin \theta+i_{b} \sin \left(\theta-\frac{2 \pi}{3}\right)\right. \\
\left.+i_{c} \sin \left(\theta+\frac{2 \pi}{3}\right)\right] \\
i_{o}=\sqrt{(1 / 3)} \times\left(i_{a}+i_{b}+i_{c}\right)
\end{gathered}
$$

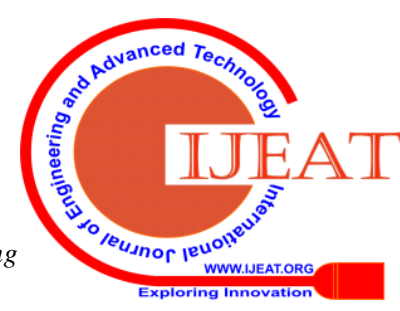




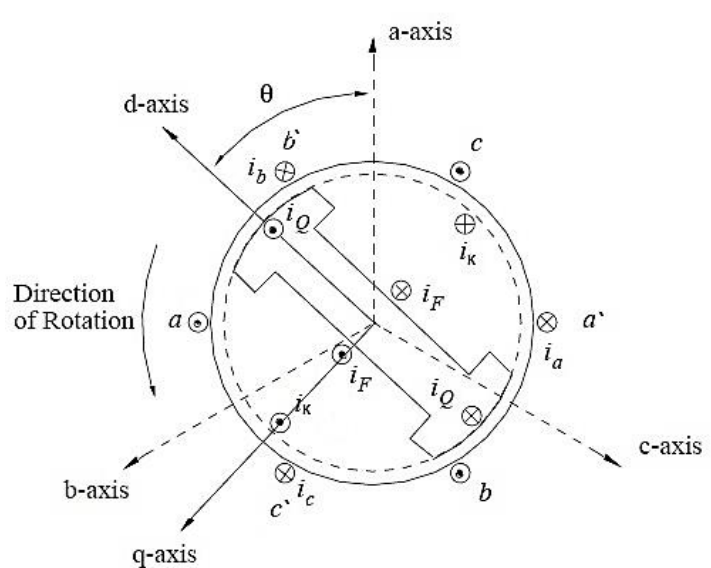

Fig.4 Park-Gorev Transformation of synchronous generator [14].

The total torque can be expressed by:

$T=\frac{3}{2} \frac{d}{d t}\left(\lambda_{d} i_{q}-\lambda_{q} i_{d}\right)$

\section{THE EMBEDDED MICROSOFT EXCEL SHEET BASED ON POWER SYSTEM STABILITY ANALYSIS}

Power systems are regarded as being non-linear systems that should operate between specified conditions to ensure reliability and stability of electricity supplies. If unstable conditions of a power system are not rectified rapidly, cascading outages and major disruptions to power supplies may occur. Packages such as Matlab can be used as a different application; Microsoft spreadsheet provides another alternative, non-tedious and sustainable solution with no need for additional software to be installed. A thorough mathematical modelling of both types of synchronous machines (Salient and Cylindrical) has been carried out before establishing the program. This software is a new educational and research desktop tool. Five different algorithms have been implemented to provide wider choice so the stability problem can be studied in details. The problem identifies when one out of four different kinds of faults is being applied to a particular generator to observe the response of the system. The limits of changing the parameters of the synchronous generator after having been subjected to a short circuit in order to optimise the stability level and the efficiency is one of the software`s tasks.

Excel worksheet is incorporated with Visual Basic Software Environment (VBSE), an Integrated Development Environment "IDE". Due to the fact that VBSE is owned by Microsoft, everyone is able to use it freely by clicking on the keyboard's buttons "Alt" and "F11" simultaneously. Since VBSE is an essential software for all computers thus it will not slow down the computer in comparison to other software e.g. Matlab. Furthermore, programming with visual basic has become popular since 1993 as well as Matlab. Lastly but most importantly, with the Mobiles and Tablets revolution, Excel can work properly on most of them. Without a doubt modern Apple's tablets have demonstrated their capability of handling complicated spreadsheet management. In spite of the fact that the absence a mouse and keyboard interface, Excel for iPad is approximately the same of its desktop counterpart.
The designed program uses the Runge-kutta method for automatically calculating the dynamic stability limit at the first angle`s swing. The method is designed to compare the levels of dynamic stability of generators when their parameters change, the duration of a short circuit, the application of measures to increase dynamic stability and the limits of changing the generator`s parameters e.g. $X_{s r}$, $X_{d}, X_{q}, T_{m}$ and $T_{r}$. This approach has allowed analyse of the effect of changing the various parameters of synchronous machines.

In connection with the above, the study of the effect of the parameters of powerful hydro and turbo-generators on the parameters of dynamic stability is highly relevant. The main attention is paid to the study of the influence of parameters on the level of dynamic stability. The effect of changing each one of the generator`s parameters has been analysed under four types of fault calculations. The software provides the results in figures as well as in graphs which makes things easy to analyse.

The EMES-PSS tool calculates the system stability level by allowing parameters of cylindrical and salient rotor generators to be altered and the power output studied for different control circuit arrangements with amplification factor $\left(\mathrm{K}_{\mathrm{f}}\right)$ that regulates rotor excitation $\mathrm{V}_{\mathrm{f}}$ in respect with different fault types. Equation (17) describes the transient voltage $\left(E_{q}^{\prime}\right)$ related to these arrangements.

$\frac{d E_{q}^{\prime}}{d t}=\frac{\left(K_{f} V_{f}-E_{q}\right)}{T_{r}}$

Where: $T_{r}=\frac{L_{f d}}{R_{f d}} \quad$ "field winding time constant".

Determining the excitation voltage, taking into account the type of Automatic Voltage Regulations (AVRs), was part of the mathematical model of the synchronous generator within this literature [10]. The equation to determine the voltage of the generator with a system of selfexcitation with respect to the field forcing is represented as:

$V_{f}=k_{f} * \frac{V_{\text {fnom }} * V}{V_{\text {nom }}}$

Where: $V_{\text {fnom }}-$ Nominal value of the excitation voltage,

$\mathrm{V}_{\text {nom }}$ - nominal voltage of the stator

$\mathrm{K}_{\mathrm{f}}=$ the multiplicity of field forcing

The value of the dynamic stability limit of power transmission is calculated for several (usually three) values of the multiplicity of the forced excitation $\mathrm{k}_{\mathrm{F}}$. The mathematical description of $\mathrm{P}=\mathrm{f}\left(\mathrm{k}_{\mathrm{F}}\right)$ allows comparison of the levels of dynamic stability of generators by changing their parameters. The limits of dynamic stability are estimated from the first variation of the angle $\delta$. It is assumed that the generators are equipped with a high-speed excitation system that provides effective excitation from the moment of the onset of a short circuit to the moment when the angle $\delta$ reaches its first maximum. The stability of the transient process is determined in the program on the basis of the investigation of the signs of slip "S" and its derivative (pS) on a short circuit. However, the term "slip" is commonly related to Induction Machines. The synchronous machine during the transient process behaves in relation to speed in the same way as an Asynchronous Machine that has two different speeds: the rotational speed of the electromagnetic field and the speed of the rotor.

Where: 
A Feasibility Solution of a Synchronous Generator for Optimisation of the System Power Stability using an Integrated Development Environment of Visual Basic-Excel

\begin{tabular}{|c|c|c|c|c|c|c|}
\hline \multicolumn{4}{|c|}{$\begin{array}{l}S=\frac{d \delta}{d t} \times \frac{1}{\omega_{s}} \\
p S=\left(T_{m}-\lambda_{d} i_{q}+\lambda_{q} i_{d}\right) / J\end{array}$} & & & \\
\hline \multicolumn{4}{|c|}{$\begin{array}{ll}\text { TABLE I. } & \text { SALIENT POLE GENERATOR } \\
& \text { PARAMETERS }\end{array}$} & \multicolumn{3}{|c|}{$\begin{array}{c}\text { TABLE II. NONSALIENT POLE GENERATOR } \\
\text { PARAMETERS }\end{array}$} \\
\hline Generator parameters in PU & $\begin{array}{l}185 \mathrm{MW}, \\
\text { 64-pole }\end{array}$ & \begin{tabular}{|l|}
$720 \mathrm{MW}$, \\
80-pole \\
\end{tabular} & \begin{tabular}{|l}
$1000 \mathrm{MW}$, \\
4-pole
\end{tabular} & Generator parameters in PU & 500 MW, 2-pole & $200 \mathrm{MW}, 2$-pole \\
\hline Power & 0.85 & 0.98 & 0.85 & Power & 0.85 & 0.85 \\
\hline Power Factor & 0.85 & \begin{tabular}{|l|l|}
1594 \\
1594
\end{tabular} & 0.85 & \begin{tabular}{|l} 
Power Factor \\
\end{tabular} & 0.85 & 0.85 \\
\hline Direct axis reactance $\left(X_{d}\right)$ & 1.66 & \begin{tabular}{|l|l|}
1.594 \\
1019
\end{tabular} & $\frac{2.35}{2.24}$ & $\begin{array}{l}\text { Direct axis reactance }\left(X_{d}\right) \\
\text {. }\end{array}$ & 2.56 & 1.869 \\
\hline $\begin{array}{l}\text { q-axis Sub-transient reactance }\left(X_{\mathrm{q}}\right) \\
\text { Synchronous reactance }\left(X_{\mathrm{S}}\right)\end{array}$ & $\begin{array}{l}1.03 \\
0.22\end{array}$ & \begin{tabular}{|l|}
1.019 \\
0.233
\end{tabular} & \begin{tabular}{|l|}
2.24 \\
0.32
\end{tabular} & q-axis Sub-transient reactance $\left(X_{q}\right)$ & 2.56 & 1.869 \\
\hline Stray rotor reactance $\left(X_{S r}\right)$ & 0.25 & & & \begin{tabular}{|l} 
Synchronous reactance $\left(X_{S}\right)$ \\
\end{tabular} & 0.24 & 0.194 \\
\hline Direct axis transient reactance $\left(X_{d}^{\prime}\right)$ & & 0.512 & 0.4536 & Stray rotor reactance $\left(X_{s r}\right)$ & & \\
\hline Direct axis stray rotor reactance $\left(X_{s r d}\right)$ & 0.196 & & & Direct axis transient reactance $\left(X_{d}^{t}\right)$ & 0.3541 & 0.3016 \\
\hline Direct axis sub-transient reactance $\left(X_{d}^{\prime \prime}\right)$ & & 0.366 & 0.4016 & Direct axis stray rotor reactance $\left(X_{s r d}\right)$ & & \\
\hline q-axis stray rotor reactance $\left(X_{s r q}\right)$ & 0.147 & & & \begin{tabular}{|l} 
Direct axis sub-transient reactance $\left(X_{d}^{\prime \prime}\right)$ \\
\end{tabular} & 0.2921 & 0.2337 \\
\hline q-axis sub-transient reactance $\left(X_{q}^{\prime \prime}\right)$ & & 0.387 & 0.44 & q-axis stray rotor reactance $\left(X_{5 r q}\right)$ & & \\
\hline Transformer reactance $\left(X_{t}\right)$ & 0.12 & 0.12 & \begin{tabular}{|l|l|}
0.12 \\
65
\end{tabular} & $\mathrm{q}$-axis sub-transient reactance $\left(X_{q}^{\prime \prime}\right)$ & 0.3634 & 0.2445 \\
\hline Turbine torque $\left(T_{j}\right)$ & $\frac{8.42}{50}$ & 2.3 & 6.5 & Transformer reactance $\left(X_{t}\right)$ & 0.12 & 0.12 \\
\hline $\begin{array}{l}\text { Time constant }\left(T_{r}\right) \\
\text { Stray rotor resistance }\left(R_{f}\right)\end{array}$ & 5.2 & 0.0033 & 0.00132 & \begin{tabular}{|l|} 
Turbine torque $\left(T_{j}\right)$ \\
\end{tabular} & 5 & 7 \\
\hline Direct axis time constant rotor excitation & 0.51 & & & Time constant $\left(T_{r}\right)$ & & \\
\hline$\left(T_{r d}\right)$ & & & & Stray rotor resistance $\left(R_{f}\right)$ & 0.000844 & 0.000904 \\
\hline Direct axis rotor resistance $\left(R_{r d}\right)$ & & 0.0469 & 0.0173 & Direct axis time constant rotor excitation $\left(T_{r d}\right)$ & & \\
\hline q-axis time constant rotor excitation $\left(T_{r q}\right)$ & 0.36 & & & Direct axis rotor resistance $\left(R_{r d}\right)$ & 0.0484 & 0.003688 \\
\hline q-axis rotor resistance $\left(R_{r q}\right)$ & & 0.0359 & 0.0231 & q-axis time constant rotor excitation $\left(T_{r}\right)$ & & \\
\hline Armature resistance $\left(R_{a}\right)$ & 0 & 0 & 0 & $\mathrm{q}$-axis rotor resistance $\left(R_{r a}\right)$ & 0.061 & 0.00108 \\
\hline Transformer resistance $\left(R_{t}\right)$ & 0 & 0 & 0 & Armature resistance $\left(R_{a}\right)$ & 0 & 0 \\
\hline Circuit breaker operating time $\left(T_{k}\right)$ & 0.12 & 0.12 & 0.12 & Transformer resistance $\left(R_{t}\right)$ & 0 & 0 \\
\hline & & & & Circuit breaker operating time $\left(T_{k}\right)$ & 0.12 & 0.12 \\
\hline
\end{tabular}

According to Asymptotic stability (Lyapunov Stability) proves that solutions which begin near the stability not only remain close enough but also eventually converge to the equilibrium. The characteristic dependences of $\delta, \mathrm{S}$ and $\mathrm{pS}$ on time are shown in Fig.4. If, at some instant $\mathrm{t}>\mathrm{T}_{\mathrm{k}}$ (time to clear the fault), the slip $\mathrm{S}>0$, and its derivative $\mathrm{pS}$ $<0$, then, as can be seen from Fig. 4(a), the angle $\delta$ has not yet reached its maximum. From the condition $\mathrm{S}<0$ and $\mathrm{pS}$ $<0$ it follows that the angle $\delta$ has already passed its maximum and will decrease in the future. This shows that the system is stable. On the other hand, for $\mathrm{S}>0$ and $\mathrm{pS}>0$, the angle $\delta$ grows indefinitely with the time, therefore, this system is instable, as seen in Fig.4 (b).

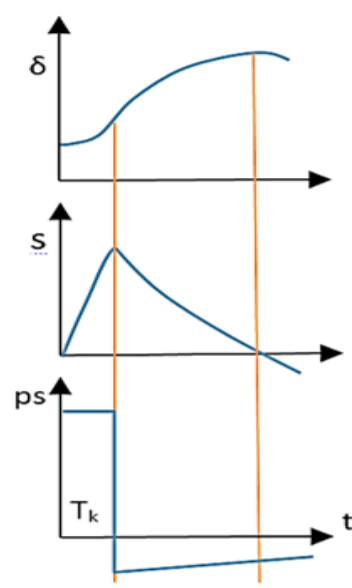

(a) Stable system

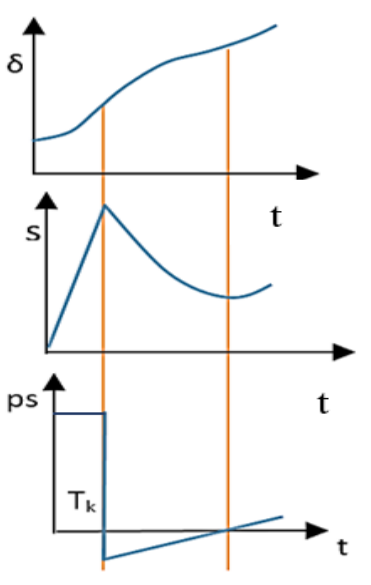

(b) Unstable system
Fig.4 Relationship of rotor angle, slip and its derivative pS.

Thus, it is obvious that all the above system`s equations must be solved until either $\mathrm{S}$ changes its sign from positive to negative for $\mathrm{pS}<0$, or $\mathrm{pS}$ does not become positive during the time when $\mathrm{S}>0$. These conditions hold for $\mathrm{t}>\mathrm{T}_{\mathrm{k}}$.
Fig. 5 illustrates a sequential change in the powers of an equivalent generator during the search for the limit of dynamic stability. The computational process terminates when the two successive values of the limiting powers differ less than the predetermined accuracy $\epsilon$. In the program, $\epsilon$ was assumed as 0.001 . The symbol $\mathrm{N}$ in the graph below represents the iteration of the process until the change of power has reached to a specific value after a period of time equals to $\mathrm{T}>\mathrm{T}_{\mathrm{K}}+0.02$, where $\mathrm{T}_{\mathrm{K}}$ is the time of the operation of the circuit breaker which was assumed to be 0.12 second.

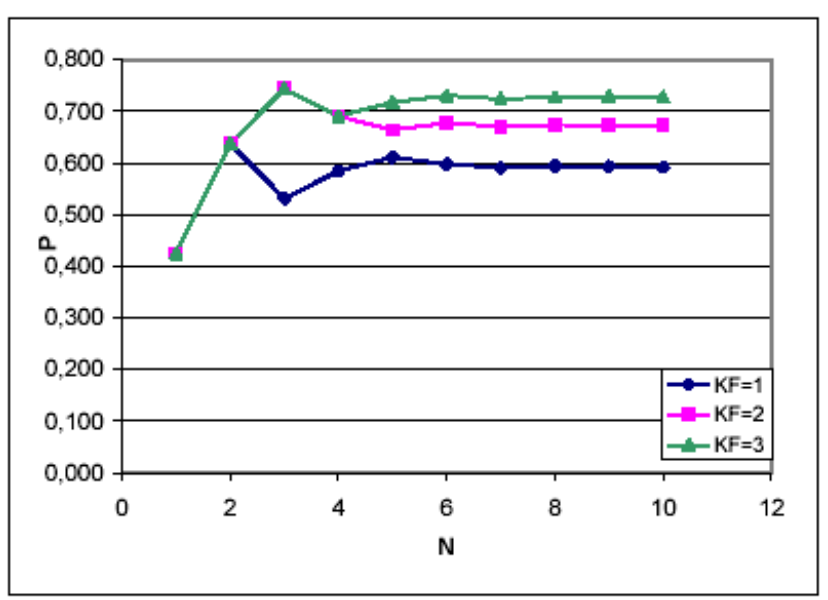

Fig.5. Power changing of Hydro-Generator (1690/18564) during the search for the magnitude of the dynamic stability limit.

It should be noted that the value of the limit of dynamic stability was found by the method described above $\left(\mathrm{X}_{\text {base }}=\right.$ $\mathrm{X}_{\mathrm{in}}=1.0, \mathrm{~S}_{\text {nom. }}=$ var.) Thus, the found value of the limit of dynamic stability can be related to the specific operating conditions of the power plant connected to the power system. 
After applying the derived modelling equations, four types of fault were implemented to study the stability level of each generator. These faults are: three phase to ground, phase to phase, phase to phase to ground and single phase to ground faults. The modelling has allowed the effects of dynamic stability, power output, transient EMFs, rotor time constant, turbine`s torque and sub-transient reactances to be analysed thoroughly. Figure 6 shows how non salient pole generator`s power output and torque vary under a phase to phase to ground fault for a $500 \mathrm{MW}$, 2-pole turbo generator with the help of $\mathrm{K}_{\mathrm{F}}$.

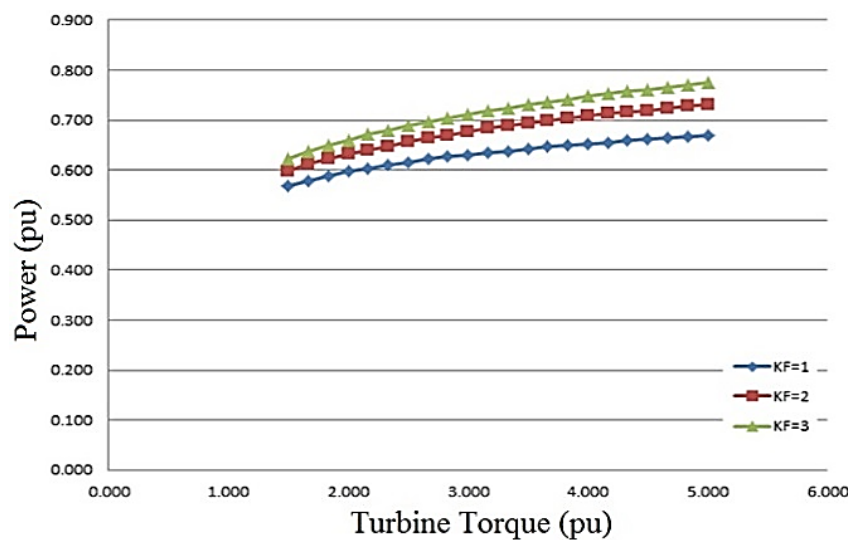

Figure 6. Stability level of a turbo generator as a function of the developed torque for different speed control settings $K_{F}$.

In Fig. 7, the results of calculating the limits of dynamic stability for phase to phase to ground fault are presented for a duration of $0.12 \mathrm{~s}$. As indicated previously, the limit value is calculated as a function of the multiplicity of the $K_{F}$ excitation boost. Forcing the excitation is assumed to be without adding inertia, and the duration of the boost is determined by the duration of the process. This means the predetermined ceiling value of the excitation voltage is kept to the maximum of its angle.

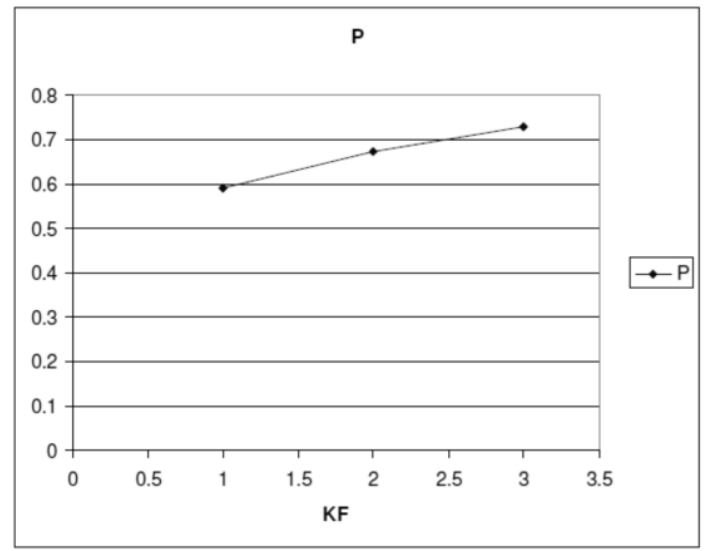

Fig.7. Dynamic Stability limit of Hydro-Generator SVF.

Based on the data in Fig. 7, it can be concluded that the hydro-generator, despite the increased values of inductive reactances, has a sufficiently high level of dynamic stability. The use of forced excitation with $\mathrm{K}_{\mathrm{F}}=2$ leads to an increase in the magnitude of the limit by $13.6 \%$, with $\mathrm{K}_{\mathrm{F}}=3$ increasing the limit by $23 \%$. The program enables the influence of other significant electromechanical parameters on the value of the limit of dynamic stability to be considered. The results of other generators` parameters will be analysed in more detail and published in future research.

\section{CONCLUSION}

The EMES-PSS provides a unique approach to generator fault conditions, as two generator design parameters can be altered simultaneously, thus enhancing stability analysis for salient and cylindrical generator types. Results show that alteration of generator design parameters allows stability problems to be considered in terms of efficiency and reliability. The primary challenge involved in power systems is maintaining stability in the operation of synchronous systems and machines. Not only the optimum stability of the system has been studied, but the cost, a deep analysis and comparison between the stabilities of the two different types of generators in addition to methods of reducing the losses will be considered in a future research.

In the Integrated Development Environment of Visual Basic and Excel software, a technique for automatically calculating the dynamic stability limit at the first angle swing is implemented. The method has been designed to compare the levels of dynamic stability of salient and cylindrical synchronous generators when changes are made to their parameters, the duration of a short circuit, the mass of a turbine and so on. The software has effectively and efficiently affirmed the optimisation solutions of the power system stability problem by using the essential computational resources.

A method for calculating transient processes in the electric power system based on the calculation of the instantaneous values of variables has also been implemented within this study. The determination of the voltages at the node points of the network is carried out with the help of expressions corresponding to the balance of the derived currents, which makes it possible to perform the calculation of transients in asymmetric short circuits and their phase disconnection.

\section{REFERENCES}

1. C. H. Cheng, Y. Y. Hsu, "Damping of Generator Oscillation Using an Adaptive Static Var Compensator ", IEEE Trans on. Power Systems, Vol. 7, N², 1992, pp. 718-724.

2. E. Sorrentino Ramirez and P. Villafuerte, "Effect of the Control of Generators and Turbines on the Transient Stability of a Power System," IEEE Latin America Transactions, vol. 14, pp. 1227 - 1234 Mar. 2016.

3. F. P. Demello and C. Concordia , "Concepts of Synchronous Machine Stability as Affected by Excitation Control," IEEE Transactions on Power Apparatus and Systems, vol. 88, pp. 316 - 329, Apr. 1969.

4. F. Milano, "An open source power system analysis toolbox," IEEE Transactions on Power Systems, vol. 20, pp. 1199 - 1206, Aug. 2005.

5. Fuchs, E. and Masoum, M. 2008. Power quality in power systems and electrical machines, Amsterdam: Academic Press/Elsevier.

6. G. Andersson, 'Dynamics and Control of Electric Power Systems', EEH-Power Systems Laboratory, Swiss Federal Institute of Technology Zurich., p. 125, 2012.

7. Gibbard, M. 2015. "Small-signal stability, control and dynamic performance of power systems”, University Of Adelaide Barr Smith.

8. Grigsby, L., 2012. The electric power engineering handbook. Boca Raton, FL: CRC Press.

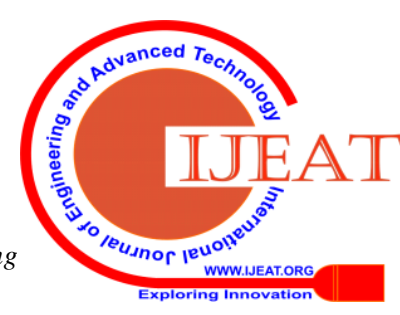


9. Kroupa, V., 2012. "Frequency stability”. Piscataway, NJ: IEEE Press.

10. IEEE Guide for Synchronous Generator Modeling Practices and Applications in Power System Stability Analyses. IEEE Std 11102002 (Revision of IEEE Std 1110-1991 [2003]): 1-72.

11. I. Kamwa, R. Grondin and Y. Hebert, "Wide-area measurement based stabilizing control of large power systems-a decentralized/hierarchical approach," IEEE Transactions on Power Systems, vol. 16, pp. 136 153, Aug. 2002.

12. Jan Machowski, Janusz W. Bialek, Dr Jim Bumby. “ Power System Dynamics: Stability and Control", 2nd Edition, October 2008, ISBN: 978-0-470-72558-0.

13. J. J. Cathey, Electric Machines: Analysis and Design Applying MatLab, McGraw Hill, 2001, pp. 477.

14. Naing Naing Htun, "Analysis of Transient Power-angle Characteristic for Synchronous Generator", International Journal of Scientific Engineering and Technology, ISSN 2319-8885 Vol.03,Issue.10 May2014, Pages:1966-197.

15. M. Vidysagar, "Nonlinear system Analysis", SIAM, Philadelphia 2002.

16. Machowski, J., Bialek, J. and Bumby, J., 2008. Power system dynamics. Chichester, U.K.: Wiley.

17. Paul Breeze, 2010, "the Cost of Power Generation”, Business Insight.

18. Pavella, M., Ernst, D. and Ruiz-Vega, D., 2000. Transient stability power systems. Boston: Kluwer Academic Publishers.

19. P. M. Anderson, A. A. Fouad, "Power system control and stability," IEEE Perss, 1994.

20. Prem Kumar, Senior Member, IEEE, Dale Fredrickson, Member, IEEE, Koushik Chanda, Member, IEEE, Stability Studies For System Dependent Generator Protection Functions,

21. Renewables Academy (RENAC), 'Frequency and voltage regulation in electrical grids', Federal Ministry for the Environmental, Nature Conservation and Nuclear Safety, Berlin, Germany, 2013.

22. R. Patel , T.S. Bhatti , D.P. Kothari, 22 July 2003, Improvement of power system transient stability by coordinated operation of fast valving and braking resistor. Published in: IEE Proceedings Generation, Transmission and Distribution (Volume: 150, Issue: 3 , 13 May 2003).

23. R. Zarate-Minano, T. Van Cutsem, F. Milano and A. J. Conejo, "Securing Transient Stability Using Time-Domain Simulations Within an Optimal Power Flow," IEEE Transactions on Power Systems, vol. 25, pp. 243 - 253, Feb. 2010.

24. Saadat Hadi, Power System Analysis, New Delhi, Tata McGraw-Hill Publishing Company Limited, 2002.

25. S.C. Savulescu, "Real-time stability in power systems", 2005, Springer.

26. The Electricity Safety, Quality and Continuity Regulations, 2002, http://www.legislation.gov.uk/uksi/2002/2665/pdfs/uksi_20022665_e n.pdf

27. Tumilty, R. and Bright, C.G. and Burt, G.M. and Anaya-Lara, Olimpo and McDonald, J.R.2007, "Applying series braking resistors to improve the stability of low inertia synchronous generators". In: CIRED 2007, 2007-05-21 - 2007-05-24.

\section{AUTHORS PROFILE}

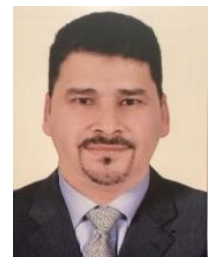

Dr. Emad Al-Mahdawi, has a $\mathrm{PhD}$ in Electrical Power Engineering from state Polytechnic university of Saint Petersburg. He has also studied in university of Kent at Social Science Department for getting the Postgraduate Certificate in Higher Education. He focuses his researches on the field of Electrical Power Engineering as well as International and National higher education. To develop solutions to electrical engineering problems using new and existing technology, the author has held Chartered Engineering from the Institution of Engineering and Technology of the United Kingdom. The author also is a fellowship of Higher Education Academy. He is presently a lecturer at MidKent College, UK. He got also a qualified higher education teaching status from University of Cranfield. 